\title{
PERSPECTIVES ON BLENDED LEARNING THROUGH THE ON-LINE PLATFORM, LABLESSONS, FOR CHEMISTRY
}

\author{
Teeba Jihad $^{1}$ (D), Edward Klementowicz ${ }^{1}$ (D), Patrick Gryczka² ${ }^{2}$, Chappel Sharrock ${ }^{3}$ (D), MacRae \\ Maxfield $^{4}$ D , Yongjun Lee ${ }^{4}$, Jin Kim Montclare ${ }^{1,3,5}$ [D \\ ${ }^{1}$ Department of Chemical and Biomolecular Engineering, New York University Tandon School of Engineering \\ (United States) \\ ${ }^{2}$ Department of Computer Science and Engineering, New York University Tandon School of Engineering \\ (United States) \\ ${ }^{3}$ Department of Chemistry, New York University College of Arts and Science (United States) \\ ${ }^{4}$ Department of Chemistry, Brooklyn Technical High School (United States) \\ ${ }^{5}$ Department of Biomaterials, New York University College of Dentistry (United States) \\ tj584@nyu.edu,.ewk.235@nyu.edu,patrick@inschoolapps.com,cs3682@nyu.edu,Mmaxfield@schools.nyc.gov, \\ Ylee12@schools.nyc.gov,montclare@nyu.edu
}

Received August 2017

Accepted January 2018

\section{Abstract}

The effectiveness of blended learning was evaluated through the integration of an online chemistry platform, LabLessons. Two modules, Formation of Hydrogen and Titration, were designed by college mentors alongside classroom chemistry teachers to engage and allow high school students to better comprehend these scientific topics. The pre-lab modules introduced the students to experiments they were expected to perform in class the following day. The modules consisted of an introduction as well as either a visualization and/or simulation specific to each topic. Students and teachers who utilized LabLessons were surveyed to establish a preliminary research on the use of technology in classrooms. Student and teacher surveys demonstrated LabLessons to be an interactive and helpful tool to improve students' understanding of conceptual ideas.

Keywords - Technology, Classrooms, Education, STEM, High School, Chemistry.

\section{Introduction}

Improvements in technology are encouraging the development of innovative approaches to learning and teaching. Traditional learning methods require the learner to obtain and absorb information from a scholarly individual. This method requires a face-to-face interaction between the learner and the instructor. The instructor is the decision maker and responsible for the information delivered in the classroom.

Online learning has shown exciting potential in promoting easier access to college by "reducing the cost and time of commuting and by allowing students to study on a schedule that is optimal for them" (Jaggars, 2011). In addition, technology-based programs have been utilized by low-income and unprepared college students who have access to platforms such as Khan Academy (www.khanacademy.org) and Udemy (www.udemy.com), which use illustrations and graphics to simplify concepts and teach the material. According to the United States Department of Education, "48 states and the District of Columbia currently support online learning opportunities that range from supplementing classroom instruction on an occasional basis to enrolling students 
in full-time programs" (U.S. Department of Education, 2015). These programs have also given students the ability to enroll in Advanced Placement and honors classes. Online programs are either "homegrown" or sponsored by private providers (U.S. Department of Education, 2015). Such platforms and programs enable the individual to learn on their own without the need for a present instructor or classroom. However, this method can eliminate communication between the teacher and the student. In addition, it can minimize interactions between students.

Traditional learning is that in which material is delivered to the learner via an instructor through face - to face interactions. Conversely, online learning involves the use of the Internet to access learning material without the physical presence of an instructor (Güzer \& Caner, 2014). It provides more flexibility and easier access to contents at anytime and anywhere (Means, Toyama, Murphy \& Rakia, 2013). However, it remains very controversial since it does not compare to traditional classroom environments, which encourage communication and improve social skills (Means et al., 2013). Therefore, scientists have approached this controversy with the idea of "blended" or "hybrid" learning.

Blended learning is gaining popularity due to its approach in combining traditional and online learning (Güzer \& Caner, 2014). In 2002, the president of Pennsylvania State University stated that "hybrid instruction is the single greatest unrecognized trend in higher education today" (Means et al., 2013). Furthermore, the North American Council for Online Learning has predicted that the blended approach is most likely to become the predominant form of teaching in the next years, surpassing traditional and online learning (Means et al., 2013). Blended learning provides a balance by preserving traditional teaching methods while integrating "wonderful technologies into [the] teaching/learning process" (Nazarenko, 2015). However, blended learning does not "yield cost savings" in comparison to online learning (Means et al., 2013). Thus, the students' and teachers' perspectives on the use of blended learning are critical to its development and implementation in K-12 education.

The amount of material that is covered in class and online varies depending on the school and the instructor. Blended learning is utilized to accommodate the various learning styles of each student, providing him/her the ability to learn the material at his/her own convenience. Scientists have described blended learning as a way to help students better understand the material through visual aids whether through images, simulations or tutorials (Michelich, 2002). Students have different learning styles and traditional teaching methods fail to accommodate all learning styles (Michelich, 2002). As a result, implementing online platforms in schools that aim to simplify complex topics via simulations and interactive modules is essential to help students better comprehend the material.

Unlike online learning, blended learning ensures that students maintain a concrete relationship with their instructor and encourages communication amongst the students. Blended learning "has the potential to improve educational productivity by accelerating the rate of learning, taking advantage of learning time outside of school hours, reducing the cost of instructional materials, and better utilizing teacher time" (U.S. Department of Education, 2015).

Studies have shown that blended learning in K-12 education is an effective method to help students better comprehend complex concepts (Gryczka, Klementowicz, Sharrock, Maxfield \& Montclare, 2016; Gryczka, Klementowicz, Sharrock \& Montclare, 2016; Chacko, Appelbaum, Kim, Zhao \& Montclare, 2015). It addresses all learning styles that traditional learning fails to accommodate.

In this paper, we are interested in students' and teachers' perspective on the use of blending learning. Recently, LabLessons, an on-line chemistry pre-laboratory (pre-lab) delivery system has been developed to provide high school students with simulations and visualizations that aid them to comprehend and prepare for in-class laboratory experiments (Gryczka, Klementowicz, Sharrock, Maxfield \& Montclare, 2016; Gryczka, Klementowicz, Sharrock \& Montclare, 2016). Modules provided by LabLessons are utilized by chemistry high school students and their input is analyzed via surveys. 


\section{Design, Methodology and Approach}

\subsection{LabLessons}

LabLessons (www.LabLessons.com) is an online platform that provides pre-labs for high school chemistry students (Gryczka, Klementowicz, Sharrock, Maxfield \& Montclare, 2016; Gryczka, Klementowicz, Sharrock \& Montclare, 2016; Chacko et al., 2015). The students using the system are each given a personal account. The site contains online pre-labs that correlate with the laboratory experiments that the student must perform in class. The pre-labs consist of instructions and basic concepts that the student must know prior to performing the lab in school. In addition, the site contains simulations and visualizations that help the students to either understand the topic at hand or the experiment they will be performing in the lab. After reading a brief introduction to the lab and watching the simulations, the students answer several questions to assess their comprehension of the topic. Once the questions are answered, the site provides the students with immediate feedback about their performance. They are informed of whether their responses are correct and, if they are incorrect, they have the option to try again and re-submit their new answers. The number of attempts to obtain the correct answer is recorded. The teachers have access to the students' answers as well as the number of attempts for each question.

LabLessons has been previously utilized by chemistry classes at Brooklyn Technical High School for two modules, Solubility and Blueprinting (Gryczka, Klementowicz, Sharrock, Maxfield \& Montclare, 2016). This year, LabLessons introduced two additional modules focused on Formation of Hydrogen and Titration. The format of the modules was similar to the previously published modules to maintain consistency and integrity of the platform.

\subsection{Modules: Formation of Hydrogen and Titration}

The Formation of Hydrogen module is comprised of a pre-lab format consisting of four questions (Figure 1). The questions are specifically designed for the students to better comprehend the concept of electrolysis. The first two questions focus on definitions to help the student understand the different types of reactions. The last two questions contain visual aids aimed at clarifying the concept of hydrogen formation. The students are to respond to the four questions and submit their answers. Instant responses of whether the answer is correct or not are generated and the students have multiple attempts to enter their responses and obtain the correct answer.

The Titration module was run after the Formation of Hydrogen. It was expanded to include an introduction, visualization, a YouTube video as well as pre-lab questions. The pre-lab begins with a short introduction, which highlights the main concepts and explains why titration is an important technique in science laboratories (Figure 2).

The introduction is then followed by a simulation illustrating a typical titration experiment. A buret containing a base of known concentration is placed above a beaker that contains an acid of unknown concentration and an indicator. In the simulation, the student begins by adding indicator into an acid solution. The student is then able to add a basic solution to the acidic solution in a drop-wise manner. When enough base has been added to titrate the acid, the solution changes color (Figure 3). When the color change occurs, the student is notified to record how much basic solution was added to the acidic solution. The volume recorded is then used to determine the concentration of the unknown acid. It is hypothesized that this simple simulation should help the students to better understand acid-base titration and improve their ability to perform the lab the next day in class without confusion.

A YouTube video is embedded in the pre-lab as well to further simplify the concept and answer any misconceptions the student may have encountered during the visualization (Figure 4). After the simulation and the video, the students are asked to answer several questions to test their understanding of titration (Figure 4). 


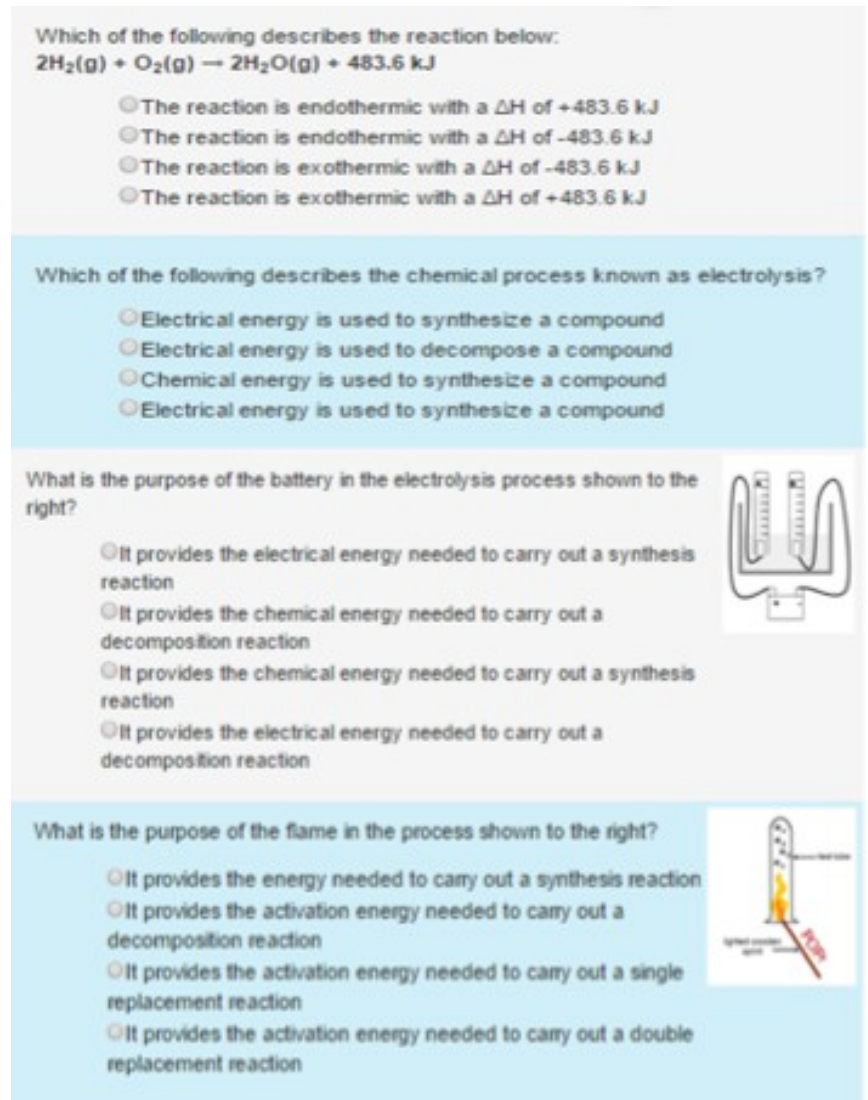

Figure 1. Pre-lab questions and visual aids created to help the students understand the purpose of a battery in an electrolysis process and a flame in hydrogen formation

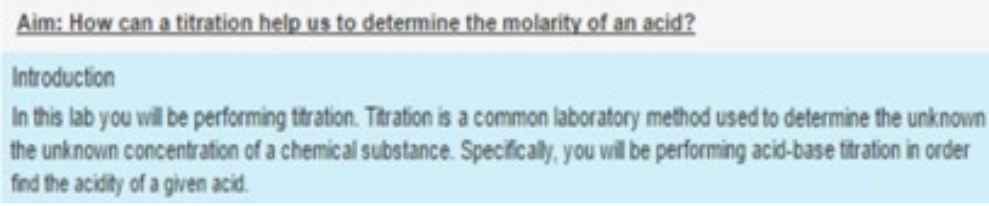

Figure 2. Objective and introduction for the Titration experiment

\begin{tabular}{|l|l|l|l|l|}
\hline Titration \\
$\begin{array}{l}\text { Containing Based of } \\
\text { Known Concentration }\end{array}$ \\
$\begin{array}{l}\text { Graduated Cylinder } \\
\text { Containing Acid of Unknown } \\
\text { Concentration and indicator } \\
\text { (likely phenolphthalein) }\end{array}$
\end{tabular}

Figure 3. Simulation for the acid-base titration experiment (A) demonstrating how an endpoint is reached (B) once enough base of known concentration has been added from the buret to the beaker containing an acid solution 


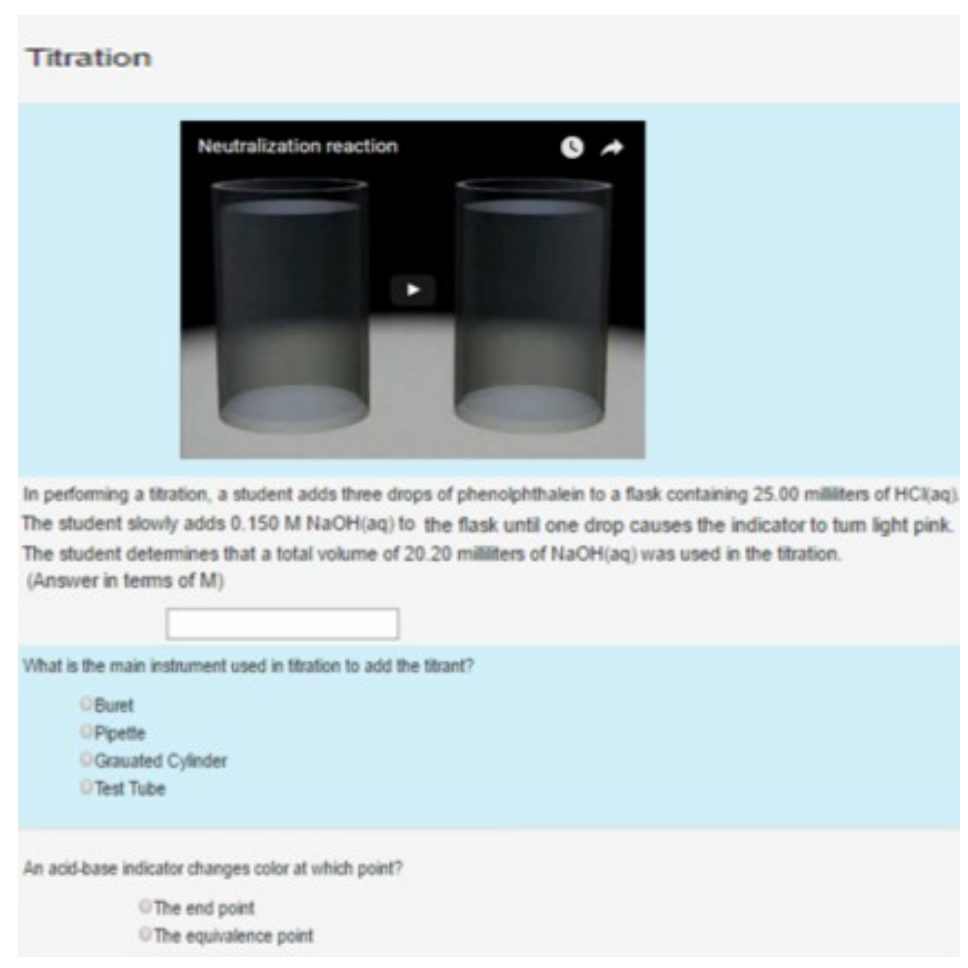

Figure 4. The embedded YouTube video along with the pre-lab questions

We hypothesize that current modules presenting simulations and visualizations help students better understand complex laboratory experiments and aid them in effectively completing the in-class lab in a timely manner. The students' academic performance in these pre-labs are expected to provide the teacher with feedback on how well the students comprehend the lab concept. The teacher can view the grades prior to the in-class lab to determine which part of the lab must be addressed in detail to help the students comprehend and conduct the lab.

LabLessons was implemented at the Brooklyn Technical High School in General Chemistry classes where freshman students were able to access the modules. Chemistry classes taught by the same instructor were randomly selected for the study.

The experimental groups utilized LabLessons in preparation for both labs. For the Formation of Hydrogen, the group consisted of $27.27 \%$ females and $72.72 \%$ males of which $50.0 \%$ were Asian, $10.0 \%$ were Hispanic and $40.0 \%$ were Caucasian. For the Titration experiment, group was composed of $36.36 \%$ females and $63.63 \%$ males with $66.66 \%$ Asian, $9.09 \%$ Hispanic and $9.09 \%$ African American and $15.15 \%$ Caucasian students.

In the fall semester, Formation of Hydrogen was carried out. During that semester, the number of students was 11. In the spring semester, Titration was carried out and the number of students was 34 . The total sample size for Titration in the experimental group was three times larger than the previous module to obtain a more accurate input.

Students were given access to their personal accounts at the beginning of the year. The site was updated with the new pre-lab. Pre-lab homework was assigned to students one week prior to performing the experiment in class, ensuring that the students were prepared for the experiment. At the end of each module, the students were required to answer several questions. There was no set limit to how many times each student could attempt to correctly answer the questions. After each failed attempt, a hint was given to aid the student in answering the question correctly.

To analyze students' as well as teachers' perspective on blended learning, surveys were distributed after completion of each module (Figures 5-7). 


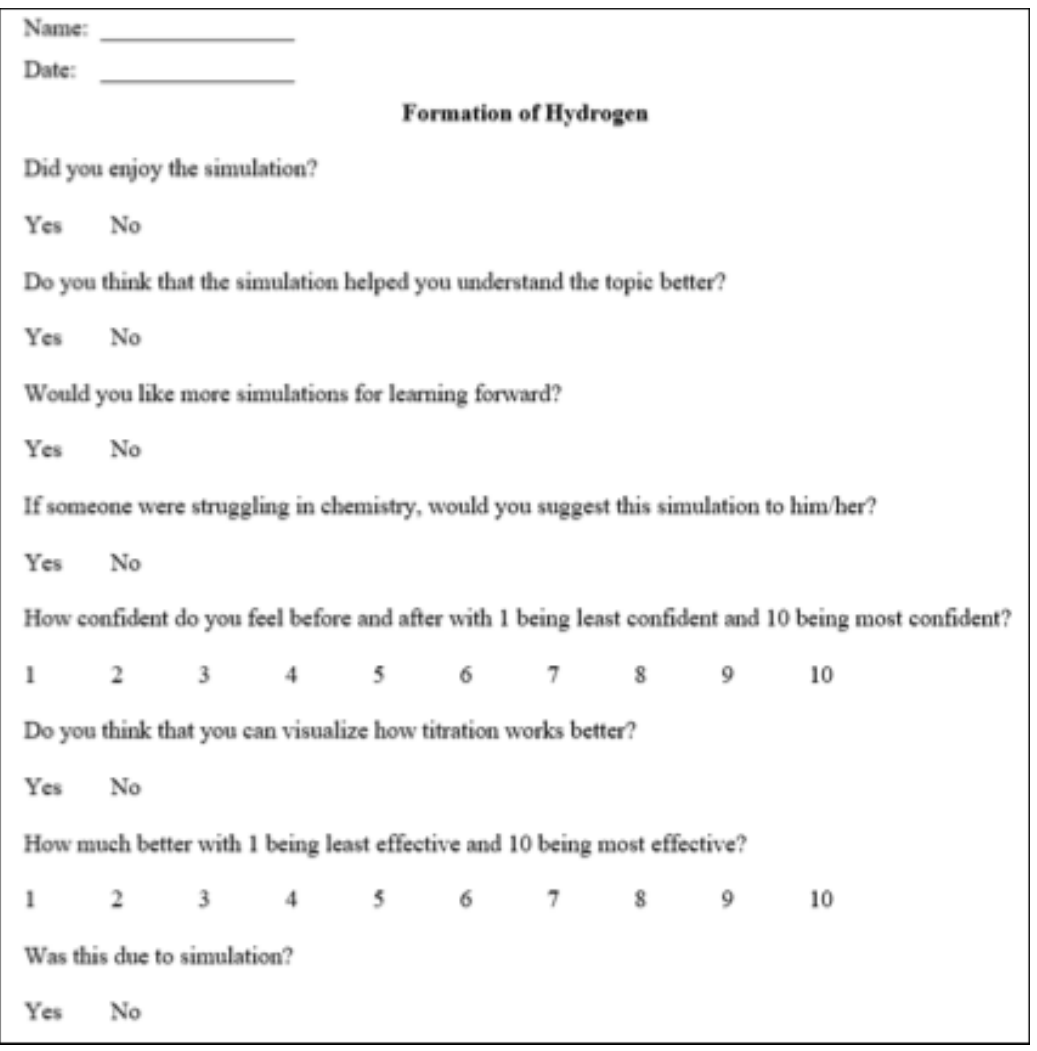

Figure 5. Student survey for the Titration experiment

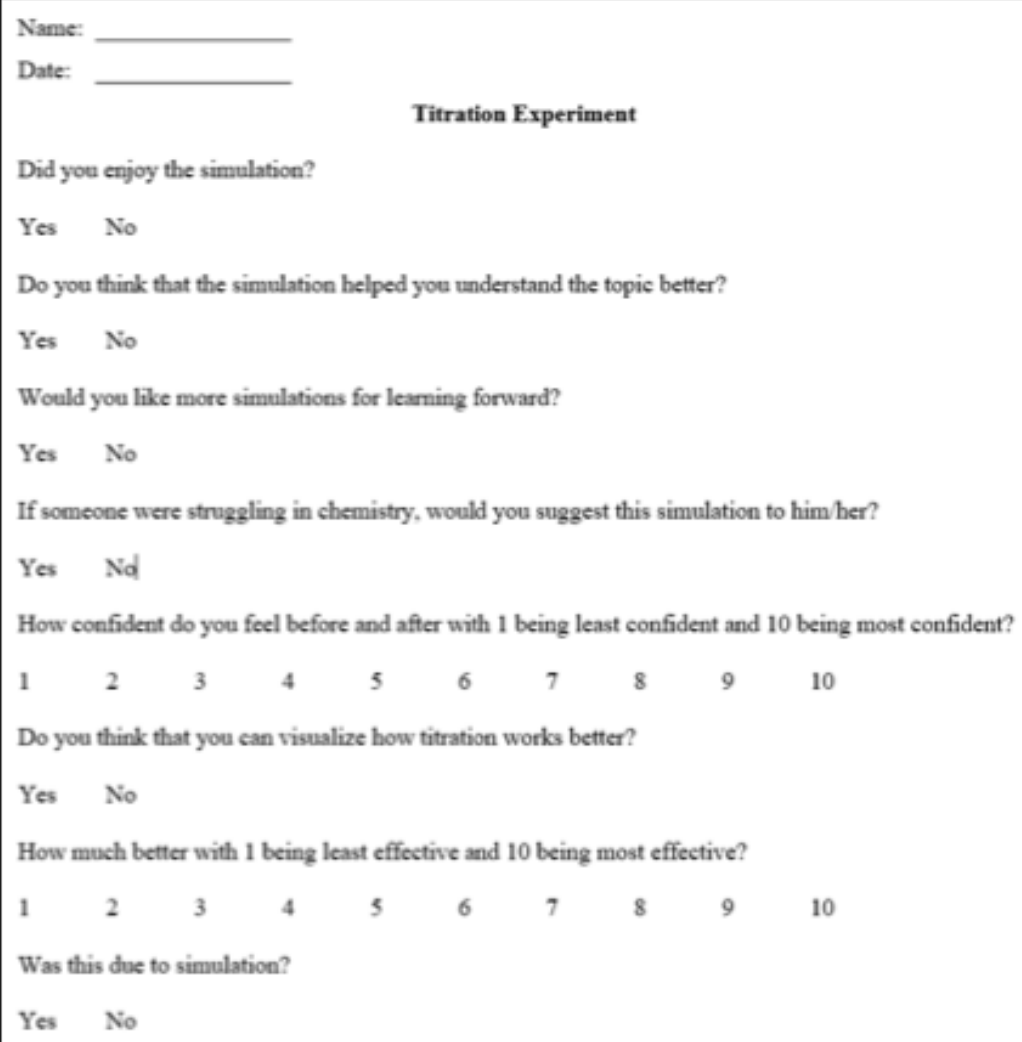

Figure 6. Student survey for the Formation of Hydrogen experiment 


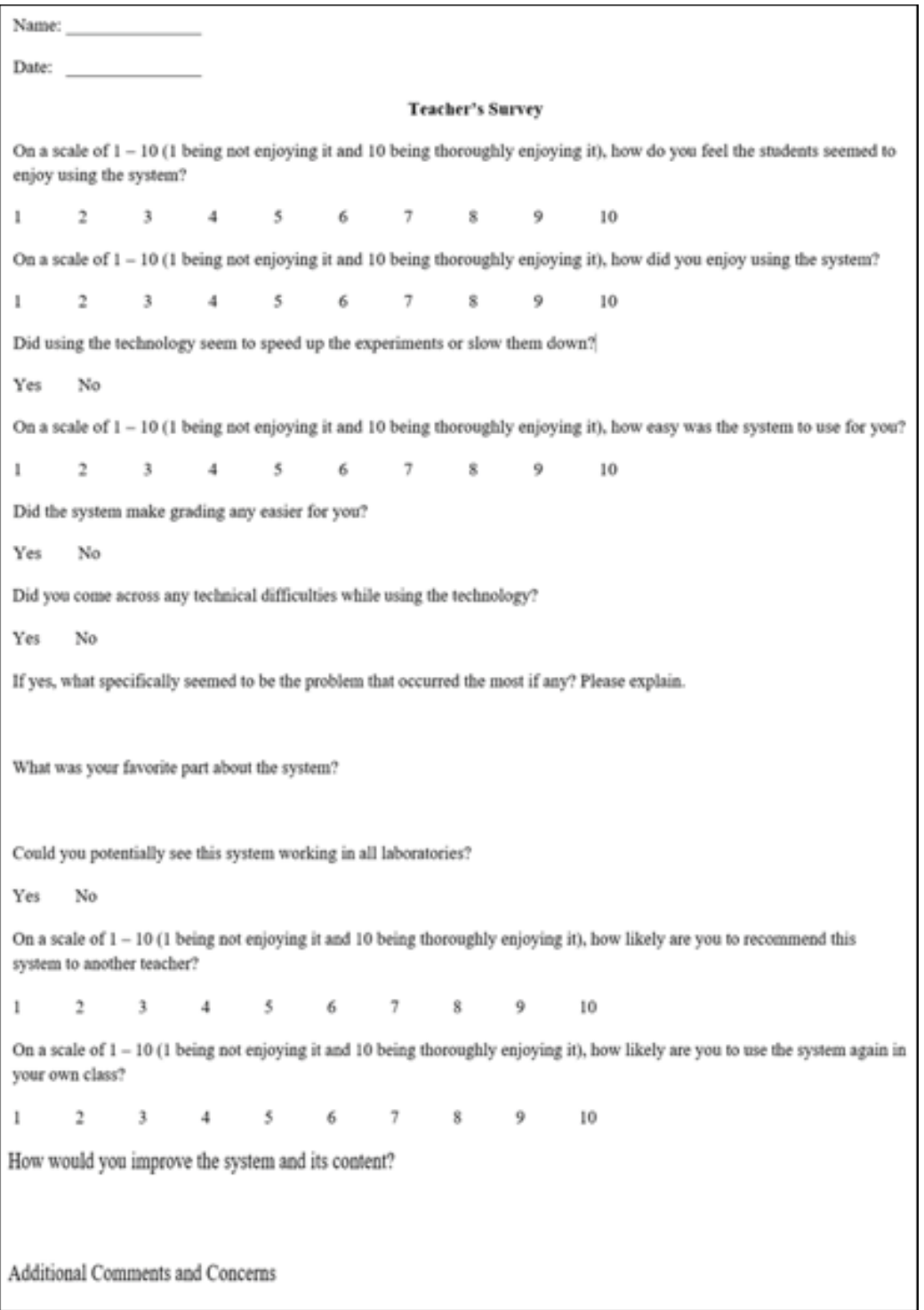

Figure 7. The teacher's survey for both Formation of Hydrogen and Titration experiments

\section{Results}

After completing the online pre-lab assignments as well as performing the experiments in school, surveys were distributed to both the students and the teachers. Obtaining a broad picture of their perspectives on the use of technology in classrooms aids us in optimizing LabLessons and creating an effective blended learning environment.

For the Formation of Hydrogen module, $76.0 \%$ of the students found the LabLessons pre-lab beneficial to understanding the topic. After completing the pre-lab, there was a $23 \%$ increase $(58 \%$ to $81 \%)$ in the students' comprehension of the lab (Figure 8) and a $28 \%(50 \%$ to $78 \%$ ) increase in their understanding of endothermic and exothermic reactions (Figure 9).

In the Titration experiment, $87.9 \%$ of the students enjoyed the simulation and $90.9 \%$ thought the simulation helped them understand the topic better (Figure 10). In addition, $87.9 \%$ indicated that they would like more simulations for learning (Figure 11) and $81.8 \%$ would recommend it to a friend struggling in chemistry (Figure 12). Finally, $100 \%$ of the students indicated they could better visualize how titration works after the simulations. 


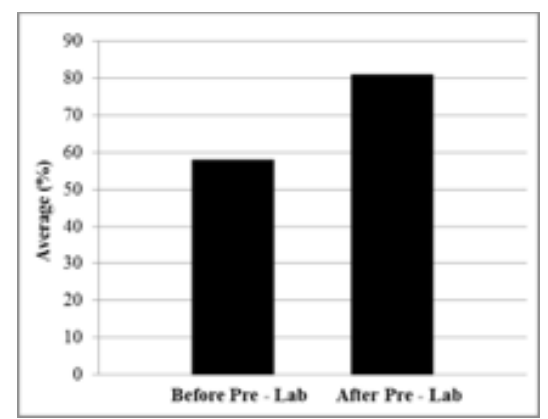

Figure 8. Responses from the Formation of Hydrogen experimental group on how well they understood the lab before and after the pre-lab component of LabLessons

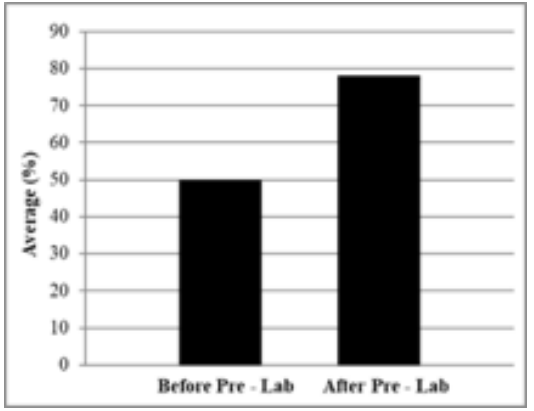

Figure 9. Responses from the Formation of Hydrogen experimental group on how well they understood endothermic/exothermic reactions before and after the pre-lab component of LabLessons

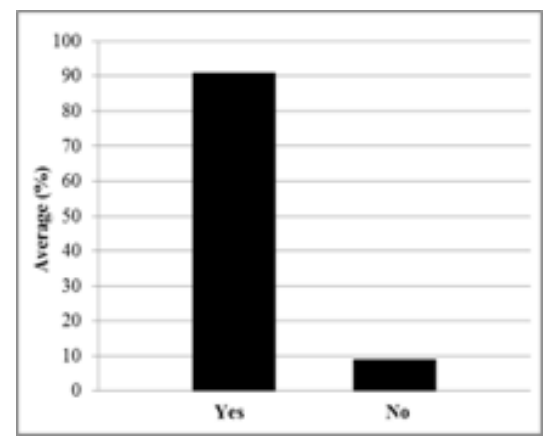

Figure 10. Responses from the Titration experimental group on whether the simulation helped them comprehend the presented concepts

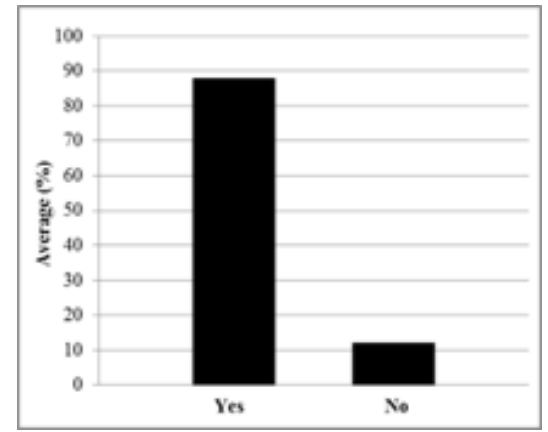

Figure 11. Responses from the Titration experimental group on whether they wanted more simulations moving forward 


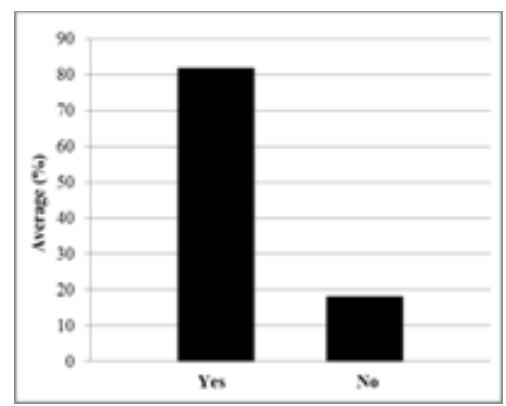

Figure 12. Responses from the Titration experimental group on whether they would suggest LabLessons to a friend

A survey was distributed to two teachers whose students utilized LabLessons to determine the effectiveness of LabLessons in their classroom (Figure 7). On a scale of one to ten, the teachers felt that the students enjoyed using the system at an "8" and that the platform helped students perform the experiments faster. In addition, one instructor stated that the "visual confirmation of conceptual ideas was an eye-opening experience for students," confirming that visual aids were a valuable tool to comprehend complex materials. The teachers also found the system extremely easy to use with no technical difficulties encountered and recommended it to other teachers. Overall, the instructor found the platform helpful for the students to use and would like to use the system again for future classes.

\section{Discussion}

In this paper, we demonstrate that students at Brooklyn Technical High School utilized LabLessons to better comprehend laboratory experiments. Two modules, Formation of Hydrogen and Titration, were used to evaluate students' and teachers' views on blended learning. LabLessons is a new platform that aims to effectively integrate technology into classrooms; providing student with additional resources to further excel in their classes. It provides students the ability to obtain an understanding of essential concepts in preparation for the in-class lab.

Additionally, LabLessons offers students the opportunity to answer laboratory questions multiple times if they were unable to do so on the first attempt. Each time they answered a question incorrectly, a clue was presented for the student to learn from the mistake. This helps the students to both correct any confusion as well as understand previously unknown information before performing the lab. By contrast, traditional paper format does not provide means for the students to understand, and learn from, their mistakes. Thus, upon entering the lab, LabLessons allowed both students and teachers to be aware of areas of misunderstanding or weakness.

For both modules, students found LabLessons to be a helpful tool in understanding chemistry. The Formation of Hydrogen module consisted only of visualizations. It did not include any simulations or videos. As a result, there was only $23 \%$ increase in the student's comprehension of the lab. On the contrary, $100 \%$ of the students who participated in the Titration module indicated that they could better visualize how titration works due to the simulation and embedded YouTube video. Thus, we argue that blended learning is necessary to improve the student's learning experience. Teachers should encourage their students to view simulations and videos relevant to course material. The teacher survey indicates that LabLessons is a useful platform for students and that visualizations and simulations confirm the conceptual theories and ideas presented in class.

According to previous research, the use of technology in classrooms functions as an assistive method to ground conceptual ideas (Gryczka, Klementowicz, Sharrock, Maxfield \& Montclare, 2016; Gryczka, Klementowicz, Sharrock \& Montclare, 2016; Chacko et al., 2015; Kim, Chacko, Zhao \& Montclare, 2014). Aside from LabLessons, our group has created multiple applications geared toward helping students to better comprehend various scientific subjects such as physics (Gryczka, Klementowicz, Sharrock \& 
Montclare, 2016) and chemistry (Gryczka, Klementowicz, Sharrock, Maxfield \& Montclare, 2016; Chacko et al., 2015; Kim et al., 2014; Lewis, Zhao \& Montclare, 2012).

Previous and current research findings confirm that the use of blended learning in schools is an effective tool. Gryczka, Klementowicz, Sharrock, Maxfield and Montclare (2016) and Gryczka, Klementowicz, Sharrock and Montclare (2016) carried out two modules, Solubility and Blueprinting, demonstrating that LabLessons improved students' performance on post-laboratory quizzes which were given after completing the LabLessons' pre-lab and the in-class experiment (Gryczka, Klementowicz, Sharrock, Maxfield \& Montclare, 2016). In the Solubility module, the control group scored an overall average of "a $93.14 \%$ with a standard error of the mean of 4.30 " while the experimental group scored "96.15\% with a standard error of the mean of 1.81" (Gryczka, Klementowicz, Sharrock, Maxfield \& Montclare, 2016). For the Blueprinting module, the control group scored "86.67\% with a standard error of the mean of 4.33" and the experimental scored "95.83\% with standard error of the mean of 0.1" (Gryczka, Klementowicz, Sharrock, Maxfield \& Montclare, 2016). For both modules, the experimental group possessed a higher retention rate then the control group.

Through blended learning, technology is used as an assistive method to traditional learning. It aids the students and the teacher rather than eliminating the role of the teacher. In this paper, we demonstrate that students enjoyed the use of technology to learn chemistry and teachers found it helpful for their students to comprehend the concepts of Formation of Hydrogen and Titration. Based on the surveys, the simulations are more effective in delivering the concepts than visualizations due to the interactive nature of their development.

\subsection{Program Outcomes}

The modules developed this year have positively impacted the students, teachers, and the college mentors. The Brooklyn Technical High School students are able to understand the concepts of titration and formation of hydrogen and carry out the experiments in a more efficient manner. The teachers did not have to spend additional time explaining laboratory material as it was covered by LabLessons. Thus, LabLessons gave teachers more time to interact with the students. They appreciated the positive use of technology in the classrooms that provided students with a positive attitude towards learning. In addition, the teachers are looking forward to the incorporation of additional modules to the platform and the expansion of LabLessons into more classes. The college mentors gained further social experiences from working with the high school students and teachers.

We are currently working on the development of a full chemistry pre-lab curriculum with respect to the New York City Regents Examination. Input obtained from the current study will be used to create a standard outline for each module with a concise introduction of the experiment, a simulation and questions.

\section{Declaration of Conflicting Interests}

The author(s) declared no potential conflicts of interest with respect to the research, authorship, and/or publication of this article.

\section{Funding}

This program was supported by the Teagle Foundation, National Science Foundation (NSF, DMR1505214, DMR-1728858 and IIP-1644681) as well as by the MRSEC Program of the NSF under Award Number DMR-0820341.

\section{References}

Chacko, P., Appelbaum, S., Kim, H., Zhao, J., \& Montclare, J.K. (2015). Integrating Technology in STEM Education. Journal of Technology and Science Education, 5(1), 5-14. http://dx.doi.org/10.3926/jotse.124 
Gryczka, P., Klementowicz, E., Sharrock, C., Maxfield, M., \& Montclare, J.K. (2016). LabLessons: Effects of Electronic Pre-labs on Student Engagement and Performance. Journal of Chemical Education, 93(12), 2012-2017. https://doi.org/10.1021/acs.jchemed.6b00394

Gryczka, P., Klementowicz, E., Sharrock, C., \& Montclare, J.K. (2016). Interactive Online Physics Labs Increase High School Students' Interest. Journal of Technology and Science Education, 6(3), 166-187. http://dx.doi.org/10.3926/jotse.191

Güzer, B., \& Caner, H. (2014). The Past, Present and Future of Blended Learning: An in Depth Analysis of Literature. Procedia Social and Behavioral Sciences, 116, 4596-4603.

https://doi.org/10.1016/j.sbspro.2014.01.992

Jaggars, S.S. (2011). Online Learning: Does It Help Low - Income and Underprepared Students? Columbia University. Retrieved August 30, 2017, from https://ccrc.tc.columbia.edu/publications/online-learninglow-income-underprepared.html

Kim, H., Chacko, P., Zhao, J., \& Montclare, J.K. (2014). Using Touch-Screen Technology, Apps, and Blogs To Engage and Sustain High School Students' Interest in Chemistry Topics. Journal of Chemical Education, 91(11), 1818-1822. https://doi.og/10.1021/ed500234z

Lewis, M.S., Zhao, J., \& Montclare, J.K. (2012). Development and Implementation of High School Chemistry Modules Using Touch-Screen Technologies. Journal of Chemical Education, 89(8), 1012-1018. https://doi.org/10.1021/ed200484n

Means, B., Toyama, Y., Murphy, R., \& Bakia, M. (2013). The Effectiveness of Online and Blended Learning: A Meta-Analysis of the Empirical Literature. Teachers College Record, 115(3), 1-47. https://www.sri.com/sites/default/files/publications/effectiveness of online andblended learning.pdf

Michelich, V. (2002). Streaming Media to Enhance Teaching and Improve Learning. The Technology Source Archives, The Univeristy of North Carolina. Retrieved August 30, 2017, from

http://www.technologysource.org/article/streaming_media_to_enhance_teaching_and_improve_learning/

Nazarenko, A. (2015). Blended Learning vs Tranditional Learning: What Works? (A Case Study Research). Procedia-Social and Behavioral Sciences, 200, 77-82. https://doi.org/10.1016/j.sbspro.2015.08.018

U.S. Department of Education (2015). Use of Technology in Teaching and Learning. Retrieved August 30, 2017, from https:/ /www.ed.gov/oii-news/use-technology-teaching-and-learning

Published by OmniaScience (www.omniascience.com)

Journal of Technology and Science Education, 2018 (www.jotse.org)

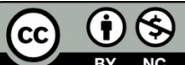

Article's contents are provided on an Attribution-Non Commercial 4.0 Creative commons International License. Readers are allowed to copy, distribute and communicate article's contents, provided the author's and JOTSE journal's names are included. It must not be used for commercial purposes. To see the complete licence contents, please visit https://creativecommons.org/licenses/by-nc/4.0/. 